\title{
Tool-Edge Wear and Wavelet Packet Transform Analysis in High-Speed Machining of Inconel 718
}

\author{
Ning Fang* - P Srinivasa Pai - Nathan Edwards \\ College of Engineering, Utah State University, U.S.A.
}

Tool-edge wear (i.e., the wear of a tool cutting edge before it is fully worn away) is among significant concerns in high-speed machining because it can result in early tool failure and deteriorated quality of machined parts. Based on extensive experimental results, this paper shows how tool-edge wear is correlated with the cutting forces and vibrations in high-speed turning of Inconel 718. The following research findings are made from the present study: 1) The development of tool-edge wear depends on the initial tool-edge geometry and the cutting conditions employed. 2) The amount of tool-edge wear varies at different measurement points along the tool cutting edge, and increases as the feed rate increases. 3) The effect of tool-edge wear on the cutting forces depends on the initial tool-edge geometry and the cutting conditions employed. 4) The traditional time-domain analysis based on the vibration amplitude is not helpful in explaining and showing the dynamic development of tool-edge wear, and wavelet packet transform helps in identifying the changes in the vibration signals in different frequency bands.

Keywords: tool-edge wear, cutting forces, cutting vibrations, wavelet packet transform, Inconel 718, high-speed machining

\section{O INTRODUCTION}

Tool wear in high-speed machining (HSM) has long been a significant concern because it shortens tool life, increases cutting forces, temperatures, and vibrations, and deteriorates the quality of machined parts or components [1] to [3]. Tool wear can be classified into different types according to its mechanisms (i.e., the reasons that cause tool wear) or its forms (i.e., the locations on a cutting tool) [4] and [5]. By mechanisms, there are adhesive wear, abrasive wear, diffusion wear, delamination wear, attrition wear, fatigue, etc. By locations, there are crater wear, flank wear, notch wear, chip-groove wear, and so on.

Extensive literature review shows that the forms of tool wear that have been widely studied are crater wear [6] and [7] and flank wear [8] and [9]. In contrast, there is little research on another important form of tool wear called tool-edge wear [10]. Tool-edge wear is defined as "the wear of a tool cutting edge before it is fully worn away [11]." Fig. 1 shows the location of tool-edge wear on a cutting tool, including a 3D view and a 2D cross-sectional view of the tool cutting edge.

As seen from Fig. 1, the location of tool-edge wear is different from those of crater wear and flank wear. Tool-edge wear is also different from tool notch wear (also called tool nose-radius wear or depth-of-cut notching in some literature). Tool notch wear occurs in the tool nose radius area and is typically measured on the tool rake face. Tool-edge wear can occur not only in the tool nose radius area, but can also occur at any other locations along the tool cutting edge. Typically, tool-edge wear is measured at a selected point on the tool cutting edge by using a fine contour measuring instrument [11]. The change in the area of the cross section of the tool cutting edge at the selected point (as shown in Fig. 1b) before and after cutting can be taken as the amount of tool-edge wear [in $\mathrm{mm}^{2}$ ] at that selected point.

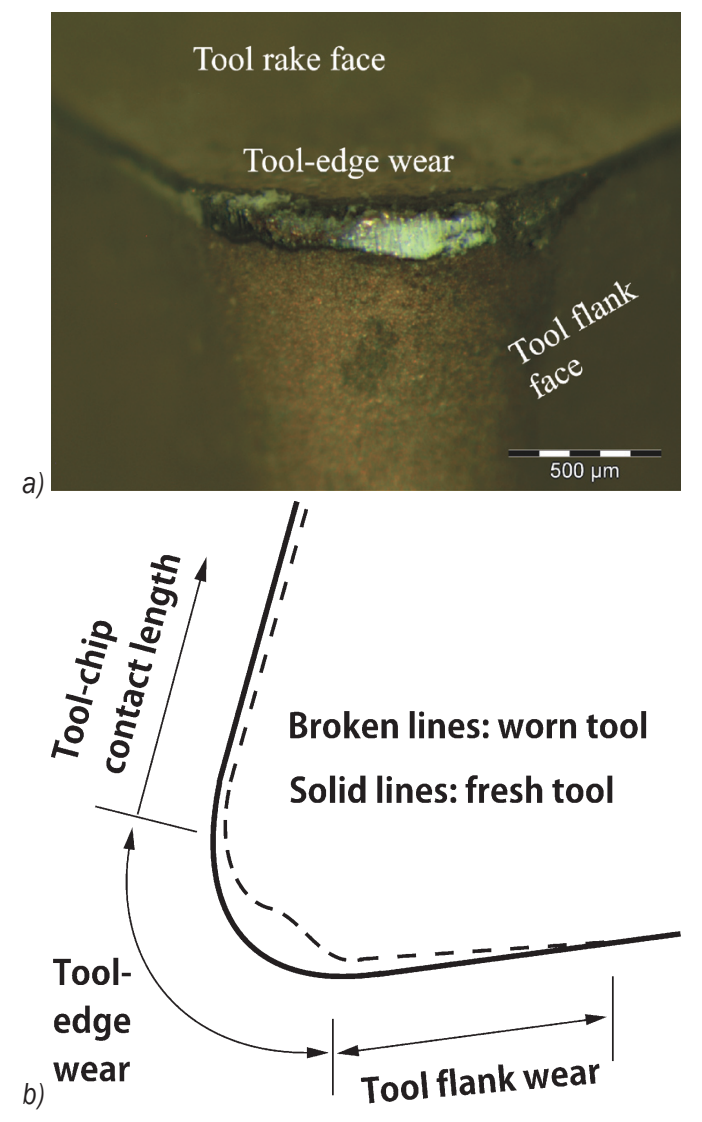

Fig. 1. Location of tool-edge wear on a cutting tool; a) 3D view and b) $2 \mathrm{D}$ cross-sectional view 
Tool-edge wear can lead to early failure of the tool cutting edge, such as severe plastic deformation and catastrophic breakage. In their 2D orthogonal high-speed machining experiments, Wu and Fang [11] have shown that tool-edge wear constantly changes the tool-edge geometry and dimensions before the tool edge is fully worn away.

The overall goal of the present study is to correlate tool-edge wear with the cutting forces and vibrations through a carefully designed set of $\mathrm{CNC}$ highspeed machining (in specific, turning) experiments that cover a wide range of cutting conditions. The present study applies an advanced signal-processing technique, called wavelet packet transform (WPT) [12] to [15], to establish the co-relationship between tool-edge wear and its associated cutting vibrations. Nickel-based superalloy Inconel 718 was selected as the work material in cutting experiments in the present study. Research by others [16] to [18] has shown that the machining of Inconel 718 often results in significant tool wear, short tool life, high cutting forces and temperature, strong vibrations, and poor quality of the machined surface.

The logic structure of this paper is as follows. Section 1 describes in detail the experimental set-up (including work material, tool material and geometry, and the cutting conditions) and the methods of measuring the tool-edge profile, the cutting forces and vibrations. Section 2 presents the experimental results of dynamic tool-edge wear and its effects on the cutting forces and vibrations. Representative examples of the tool-edge profiles and the variations of the cutting forces and vibration amplitudes at different cutting time intervals are provided. Section 3 performs time-frequency domain analysis of the vibration signals via wavelet packet transform. Representative examples of the third-level wavelet packet decomposition of vibration signals at different cutting time intervals are also provided. The major research findings are summarized at the end of this paper.

\section{EXPERIMENTAL PROCEDURE}

\subsection{Experimental Set-Up}

A CNC turning center (HAAS SL10) was employed in high-speed finish turning. Table 1 summarizes the major experimental set-up. To meet the cutting speed requirement in high-speed machining and to accelerate the tool-edge wear process, the cutting speed [125 to $275 \mathrm{~m} / \mathrm{min}$ ] was four to nine times higher than that typically employed $[30 \mathrm{~m} / \mathrm{min}]$ in conventional machining of Inconel 718. The feed rate [0.01 to $0.10 \mathrm{~mm} / \mathrm{rev}$ ] was the same magnitude as the tool edge radius [0.04 to $0.07 \mathrm{~mm}$ ] of the cutting tools to magnify the effect of tool-edge wear. The depth of cut $[0.8 \mathrm{~mm}]$ was the same as the tool nose radius. The tool nose radius and the tool edge radius are two different concepts, and they are measured in different geometrical planes in $3 \mathrm{D}$ space. No coolants were employed in the cutting experiments to facilitate the collection of the cutting force and vibration signals.

Table 1. The major experimental set-up

\begin{tabular}{|c|c|}
\hline Variables & Specifications \\
\hline Work material & Inconel 718 \\
\hline Workpiece dimension & $\begin{array}{l}\text { Solid cylindrical bar with the diameter of } \\
45 \mathrm{~mm}\end{array}$ \\
\hline Tool insert & $\begin{array}{l}\text { Flat-faced TPG } 432 \text { (made by Kennametal } \\
\text { Inc.) }\end{array}$ \\
\hline Tool material & $\begin{array}{l}\text { Cemented carbide (KC 8050) with TiC/TiN/ } \\
\text { TiCN coating }\end{array}$ \\
\hline Tool working rake angle & $5^{\circ}$ \\
\hline $\begin{array}{l}\text { Tool working side } \\
\text { cutting edge angle }\end{array}$ & $0^{\circ}$ \\
\hline $\begin{array}{l}\text { Tool working flank } \\
\text { angle }\end{array}$ & $6^{\circ}$ \\
\hline Tool nose radius & $0.8 \mathrm{~mm}$ \\
\hline Tool edge radius & Varied from 40 to $70 \mathrm{~mm}$ \\
\hline Cutting speed & $125,225,275 \mathrm{~m} / \mathrm{min}$ \\
\hline Feed rate & $0.01,0.04,0.10 \mathrm{~mm} / \mathrm{rev}$ \\
\hline Depth of cut & $0.8 \mathrm{~mm}$ \\
\hline Coolants & None \\
\hline
\end{tabular}

In order to study the dynamical development of tool-edge wear and its effects on the cutting forces and vibrations, each cutting experiment was carried out for one second and then repeated nine times with the same cutting conditions. The results of the cutting tests showed that tool wear developed very rapidly due to the use of high cutting speeds. The tool cutting edge was initially fresh in the first cut and was then worn out in the subsequent second, third, forth, ..., ninth cuts. For each cut, the tool-edge profile was measured offline, and the cutting forces and vibrations were measured online.

\subsection{Work Material}

The work material employed in the present study was commercially available, nickel-based superalloy Inconel 718. The work material has the following chemical compositions in percentage of weight: $\mathrm{Ni}$ (+Co): 50 to $55 \%$; $\mathrm{Cr}$ : 17 to $21 \%$; $\mathrm{Nb}(+\mathrm{Ta}): 4.75$ to 5.5\%; Mo: 2.8 to 3.3\%; Ti: 0.65 to $1.15 \%$; Co: $1.0 \%$; Mg: $0.35 \%$; $\mathrm{Cu}: 0.3 \%$; Si: $0.35 \%$; $\mathrm{Al}: 0.2$ to $0.8 \%$; $\mathrm{C}$ : 
0.08\%; Fe: Balance. The heat treatment conditions were as follows: one hour at 954 to $982{ }^{\circ} \mathrm{C}$, air cool, eight hours at $718{ }^{\circ} \mathrm{C}$, cool $56{ }^{\circ} \mathrm{C} / \mathrm{h}$ to $621{ }^{\circ} \mathrm{C}$, hold eight hours, and finally air cool.

\subsection{Tool Inserts and the Measurement of the Tool-Edge Profile}

A Mitutoyo type-SV602 fine contour measuring instrument was employed to measure (off-line) the profile of fresh or worn tool cutting edges for each cut. Due to manufacturing errors in the commercial tool inserts, the tool-edge profile of a fresh tool insert was not uniform along the tool cutting edge. The tooledge profile was measured at three locations along the cutting edge, as shown in Fig. 2. The center point was at the middle position of the curved tool cutting edge. The inner point was close to the machined surface. The outer point was close to the workpiece shoulder. In machining, the actual tool edge engagement with the work material occurred from the outer point to the inner point.

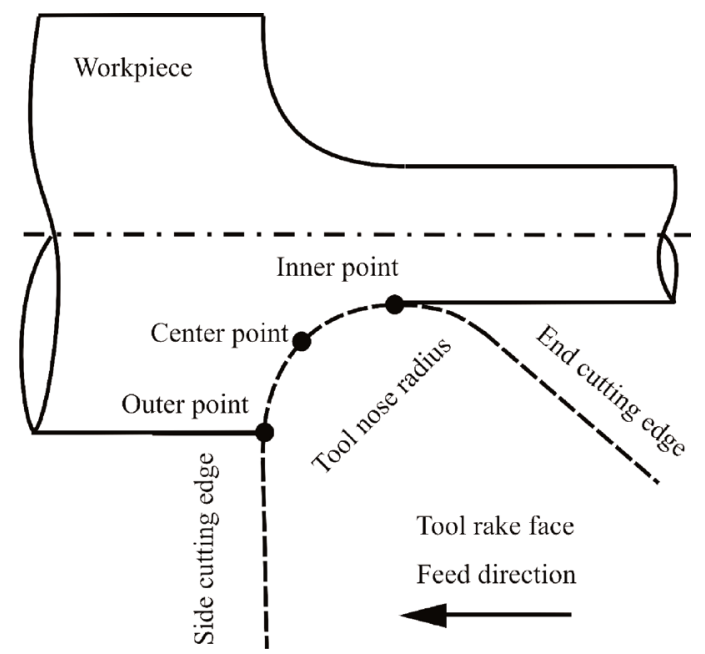

Fig. 2. Location of the three measurement points along the tool cutting edge

More than 20 tool inserts were measured, and six tool inserts with the most uniform distribution of the tool edge radius along the tool cutting edge were finally selected for use in the cutting experiments. The edge radii of these six "fresh" tool inserts at each measurement points are listed in Table 2, where $V_{\mathrm{c}}$ is the cutting speed $[\mathrm{m} / \mathrm{min}], f$ is the feed rate $[\mathrm{mm} / \mathrm{rev}]$, and $a_{\mathrm{p}}$ is the depth of cut [mm]. Tool inserts \#1 to \#3 had the tool edge radius between 61.1 to $65.3 \mathrm{~mm}$ and were employed to study the effect of tool-edge wear under varying cutting speed conditions. Tool inserts \#4 to \#6 had the tool edge radius between 45.2 to 46.6 $\mathrm{mm}$ and were used to study the effect of tool-edge wear under varying feed rate conditions. After cutting, the machine tool was stopped every one second (i.e., the cutting time interval was one second) in order to measure (offline) the profile of worn tool edges at each of the three measurement points on each tool insert.

Table 2. Six tool inserts employed in the cutting experiments

\begin{tabular}{cccccccc}
\hline \multirow{2}{*}{ Tool } & \multicolumn{3}{c}{ Cutting conditions } & \multicolumn{4}{c}{ Tool edge radius [mm] } \\
\cline { 2 - 8 } & $V_{c}$ & $f$ & $a_{p}$ & Inner & Center & Outer & Aver. \\
\hline \#1 & 125 & 0.10 & 0.80 & 60.5 & 63.8 & 67.8 & 64.0 \\
\#2 & 225 & 0.10 & 0.80 & 60.8 & 65.3 & 69.8 & 65.3 \\
\#3 & 275 & 0.10 & 0.80 & 59.2 & 60.1 & 64.1 & 61.1 \\
\#4 & 225 & 0.01 & 0.80 & 42.7 & 45.4 & 48.8 & 46.6 \\
\#5 & 225 & 0.04 & 0.80 & 43.8 & 43.7 & 48.1 & 45.2 \\
\#6 & 225 & 0.10 & 0.80 & 43.2 & 47.3 & 48.9 & 46.5 \\
\hline
\end{tabular}

\subsection{Measurement of the Cutting Forces}

For each cutting time interval, the cutting forces were measured online using a system that consisted of a Kistler 9257B, quartz three-component dynamometer; a Kistler 5010 B multi-channel, dual-mode charge amplifier; and a computer data acquisition system (Labview). A MATLAB code was written to filter the high-frequency noise from the collected force signals and determine the three components of the cutting forces, namely the cutting force $F_{c}$, the feed force $F_{f}$, and the passive force $F_{p}$. These three forces are in the tangential $[x$ - or the cutting speed], axial [y- or the feed rate], and radial $[z$ - or the depth of cut] direction, respectively.

\subsection{Measurement of the Cutting Vibrations}

While the cutting forces were measured online by the Kistler 9257B dynamometer, the cutting vibration signals were simultaneously measured online for each cutting time interval via a 356A63 Triaxial ICP accelerometer that was fixed onto the tool holder through an insulation screw hole. The collected vibration signals were subjected to post-processing in both the time domain and the time-frequency domain. In the time domain, the root mean square $(R M S)$, which is the average of the squared values of the vibration amplitude, was calculated. The $R M S$ gives positive values that can be used for vibration analysis. In the time-frequency domain, wavelet packet transform analysis was performed and will be described in detail in a subsequent section of this paper. 


\section{DYNAMIC VARIATION OF TOOL-EDGE WEAR AND ITS EFFECTS}

\subsection{Profile and Development of Dynamic Tool-Edge Wear}

Figs. 3 and 4 show two representative examples of the $2 \mathrm{D}$ tool-edge profile measured at different cutting time intervals for tool inserts \#3 and \#4, respectively. In Figs. 3 and 4, the first row is the tool-edge profile of a fresh tool, the second row is the tool-edge profile after cutting for 2 seconds, and the third row is the tool-edge profile after cutting for 9 seconds. The tooledge profile includes the tool rake face on the left side and the tool flank face on the right side of the profile.

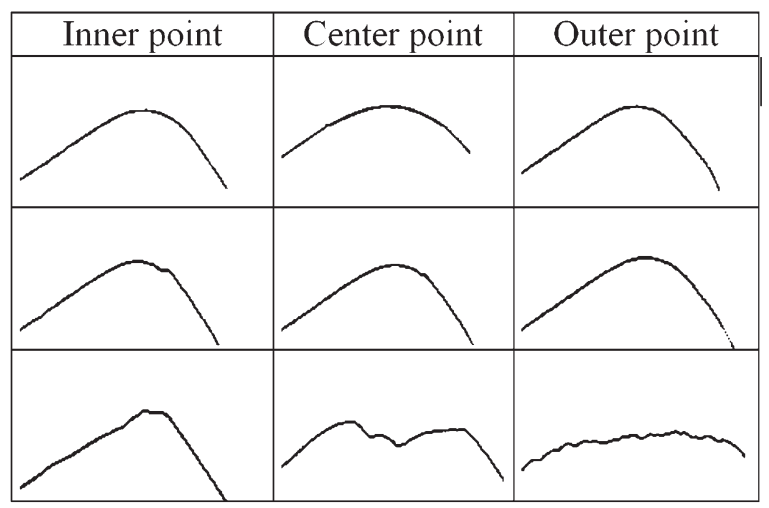

Fig. 3. Representative examples of the $2 D$ tool-edge profile measured at different cutting time intervals; tool insert \#3 under the cutting conditions of $V_{c}=275 \mathrm{~m} / \mathrm{min}, f=0.1 \mathrm{~mm} / \mathrm{rev}$,

$$
a_{\mathrm{p}}=0.80 \mathrm{~mm}
$$

Note that tool insert \#3 was employed at the relatively larger feed rate of $0.10 \mathrm{~mm} / \mathrm{rev}$. Tool insert \#4 was employed at the small feed rate of $0.01 \mathrm{~mm} /$ rev, in which case the undeformed chip thickness was much smaller than the initial tool-edge radius. The following observations are made:

1) As the cutting continues, tool-edge wear develops either rapidly or slowly, depending on the initial tool-edge geometry and initial cutting conditions employed. At all measurement points, tool-edge wear are severer and more visible at 9 seconds than that at 2 seconds, as can be seen clearly from both Figs. 3 and 4.

2) The profile of tool-edge wear dynamically varies and often has irregular shape. This can be clearly seen from the profile measurements at the center and outer points in Fig. 3.

3) Tool-edge wear increases from the outer point, through the center point, to the inner point. This is because the outer point corresponds to the shear zone with the largest undeformed chip thickness, which results in highest tool-chip friction at the outer point.

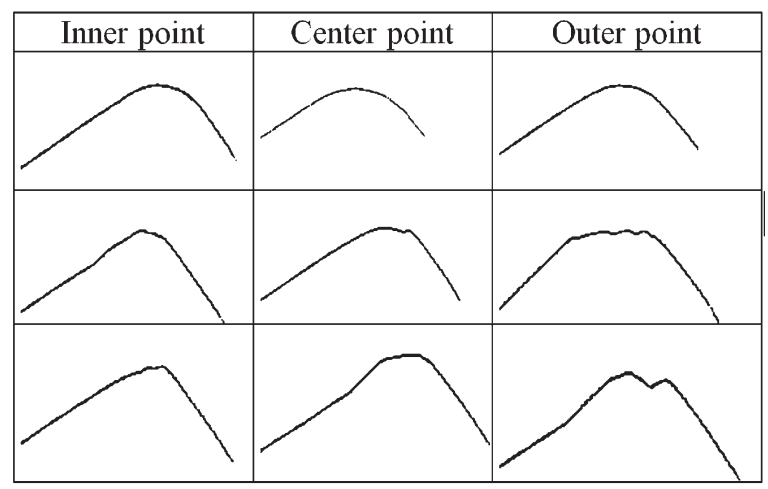

Fig. 4. Representative examples of the $2 D$ tool-edge profile measured at different cutting time intervals; tool insert \#4 under the cutting conditions of $V_{c}=225 \mathrm{~m} / \mathrm{min}, f=0.01 \mathrm{~mm} / \mathrm{rev}$,

$$
a_{\mathrm{p}}=0.80 \mathrm{~mm}
$$

4) Tool-edge wear increases as the feed rate increases. In Fig. 3, the work material undergoes more significant shear deformation and the tool-chip contact length is larger due to the relatively larger feed rate of $0.10 \mathrm{~mm} / \mathrm{rev}$. In Fig. 4, the "plowing" action (rather than the shear deformation) dominates and the tool-chip contact length is limited due to the use of small feed rate of $0.01 \mathrm{~mm} / \mathrm{rev}$. Less tool-edge wear can be observed in Fig. 4 when compared to Fig. 3.

\subsection{Effect of Dynamic Tool-Edge Wear on the Cutting Forces}

Because tool-edge wear varies from point to point on the tool cutting edge, the best way to represent overall tool-edge wear is using the cutting time interval. Figs. 5 and 6 quantitatively show how dynamic tool-edge wear - represented by the cutting time interval - affects the three components of the cutting forces under varying cutting speeds and feed rates, respectively. For comparison purposes, the scales of the vertical axes in these figures are made the same.

Fig. 5 shows that all three components of the cutting forces increase with increasing tool-edge wear at the cutting speed of $125 \mathrm{~m} / \mathrm{min}$. However, the increasing trend of the cutting forces is not significant at the relatively higher cutting speeds of 225 and 275 $\mathrm{m} / \mathrm{min}$. In all three sub-figures in Fig. 5, the cutting force $F_{c}$ is higher than the feed force $F_{f}$, and the passive force $F_{p}$ is the smallest among the three force components.

Fig. 6 shows that all three components of the cutting forces increase with increasing tool-edge wear 
at the feed rates of 0.01 and $0.10 \mathrm{~mm} / \mathrm{rev}$. However, the increasing trend of the cutting forces is not significant at the feed rate of $0.04 \mathrm{~mm} / \mathrm{rev}$. Under the feed rate of 0.04 and $0.10 \mathrm{~mm} / \mathrm{rev}$ (see Figs. $6 \mathrm{~b}$ and $6 c$ ), the cutting force $F_{c}$ is higher than the feed force $F_{f}$. Under the small feed rate of $0.01 \mathrm{~mm} / \mathrm{rev}$ (see Fig. 6a), the feed force $F_{f}$ is higher than the cutting force $F_{c}$. This latter phenomenon is directly associated with the

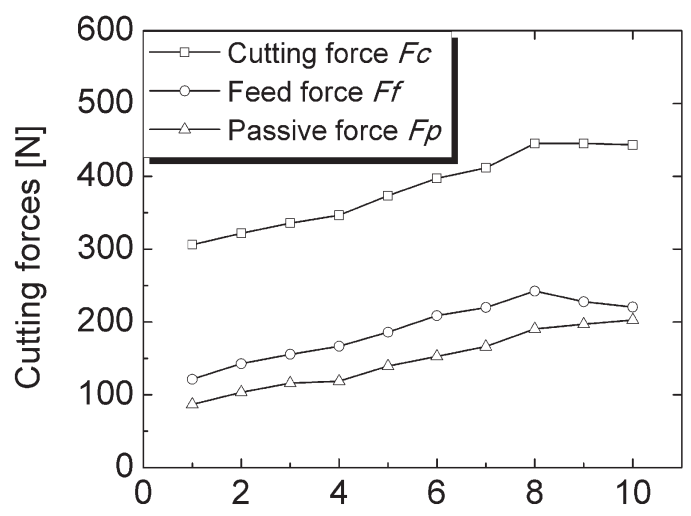

a)

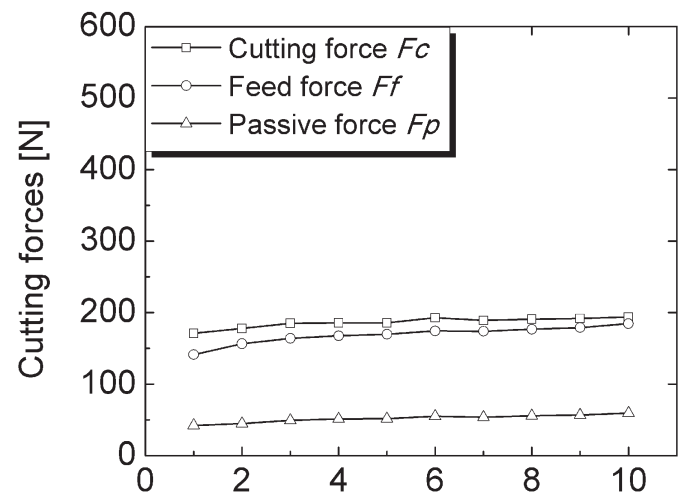

b)

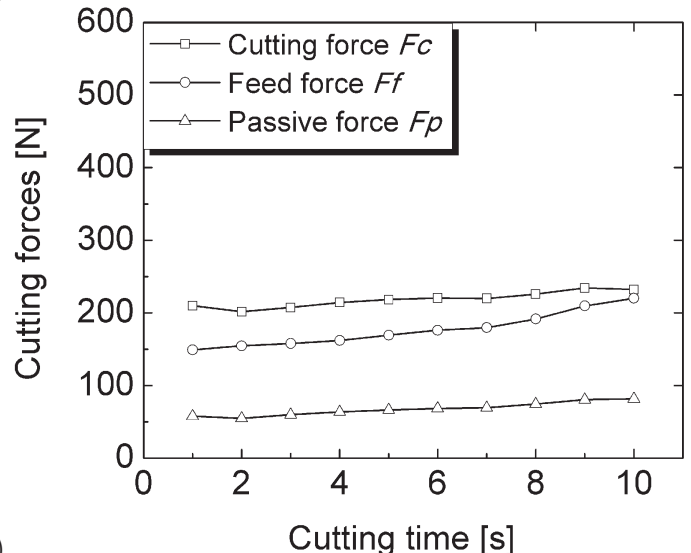

Fig. 5. The cutting forces vs. the cutting time at the feed rate of $0.10 \mathrm{~mm} / \mathrm{rev}$ and the cutting speed of a) $125 \mathrm{~m} / \mathrm{min}$, b) $225 \mathrm{~m} /$ min, and c) $275 \mathrm{~m} / \mathrm{min}$; tool inserts \#1 to \#3 were employed tool-edge effect. A significant amount of theoretical and experimental studies in 2D machining [17] to [19] have shown that the thrust force (corresponding to the feed force in 3D machining) can be higher than the cutting force if the undeformed chip thickness is greatly lower than the tool edge radius.

The above experimental results reveal that the effect of dynamic tool-edge wear on the cutting

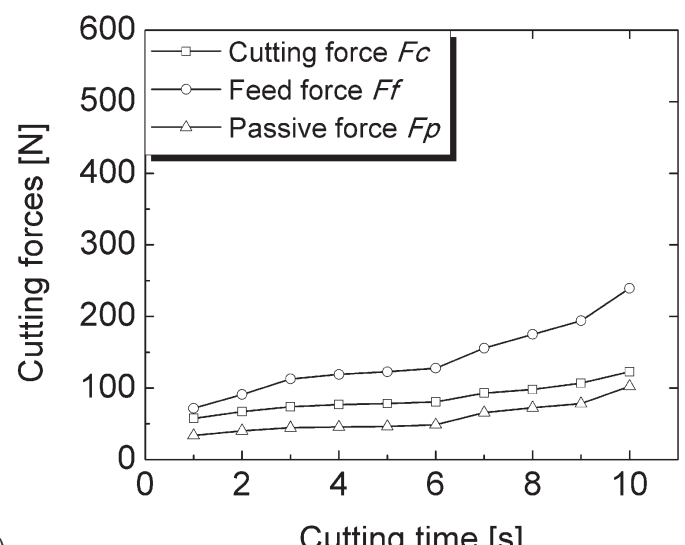

a)

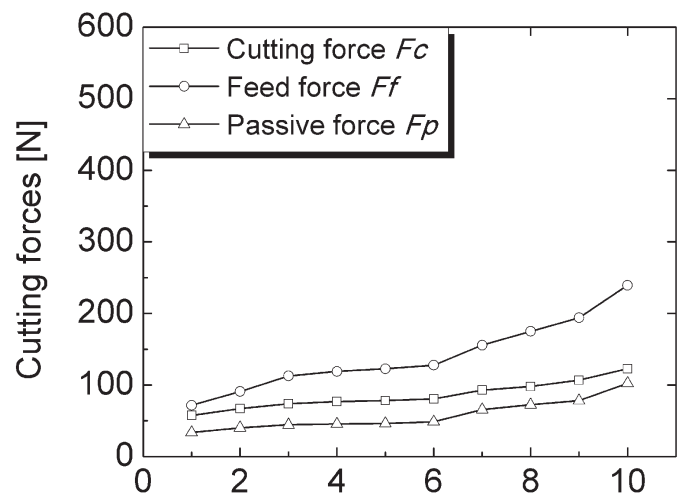

b)

Cutting time [s]

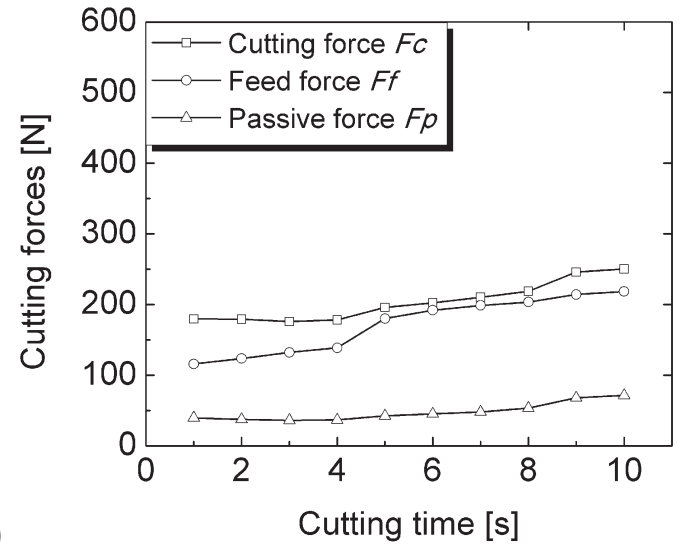

Fig. 6. The cutting forces vs. the cutting time at the cutting speed of $225 \mathrm{~m} / \mathrm{min}$ at the feed rate of a) $0.01 \mathrm{~mm} / \mathrm{rev}$, b) $0.04 \mathrm{~mm} / \mathrm{rev}$, and c) $0.10 \mathrm{~mm} / \mathrm{rev}$; tool inserts \#4 to \#6 were employed 
forces highly depends on particular cutting conditions employed as well as the initial tool-edge geometry. In the final analysis, the cutting forces are the results of interactions among tool-edge wear, cutting conditions, tool geometry, and so on.

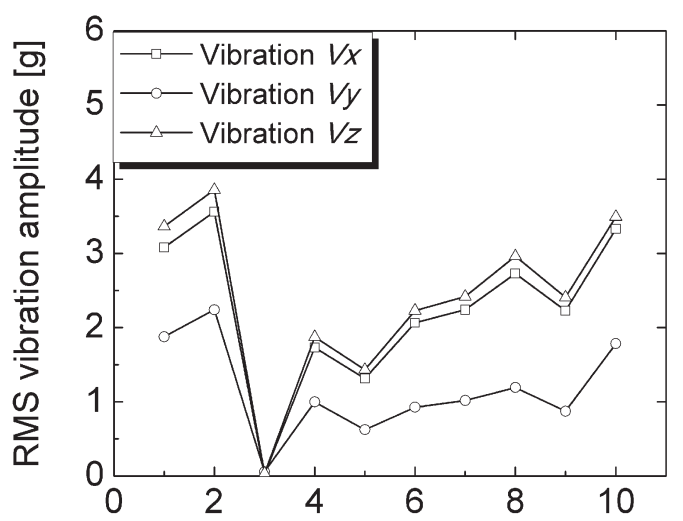

a)

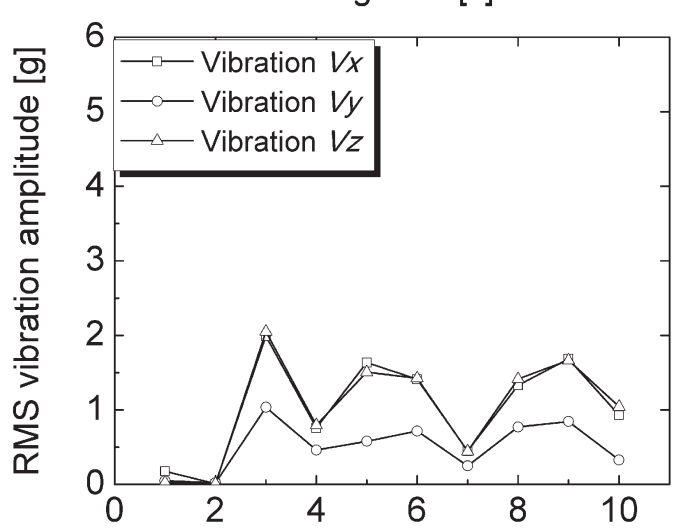

b)

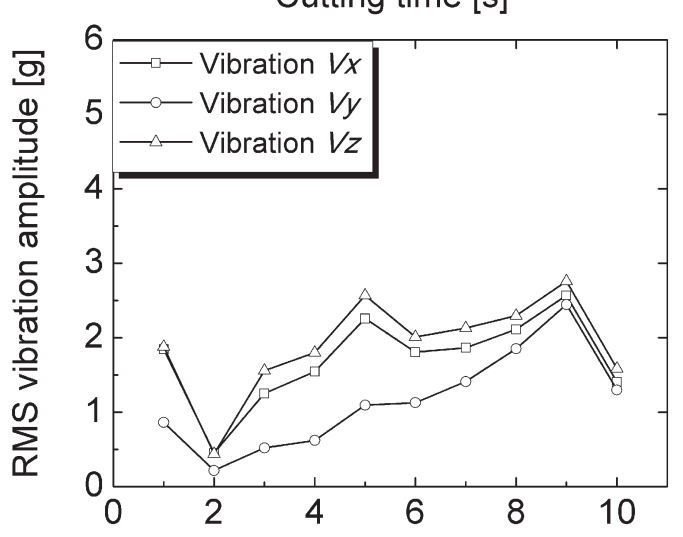

c)

Cutting time [s]

Fig. 7. The vibration amplitude vs. the cutting time at the feed rate of $0.10 \mathrm{~mm} / \mathrm{rev}$ and the cutting speed of a) $125 \mathrm{~m} / \mathrm{min}$, b) $225 \mathrm{~m} /$ min, and c) $275 \mathrm{~m} / \mathrm{min}$; tool inserts \#1 to \#3 were employed

\subsection{Effect of Dynamic Tool-Edge Wear on the RMS Vibration} Amplitude

The $R M S$ vibration amplitude is the square root of the average of the squared values of the vibration

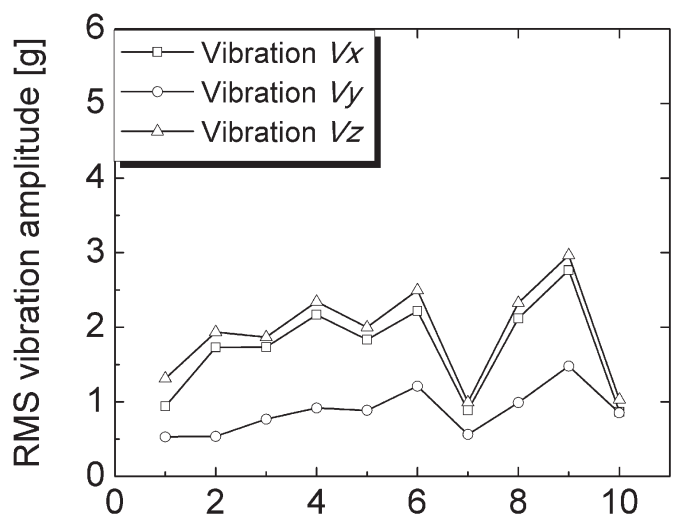

a)

Cutting time [s]

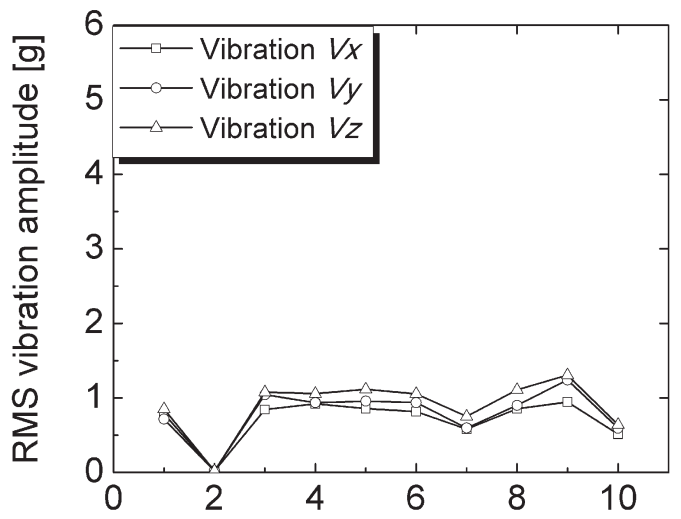

b)

Cutting time [s]

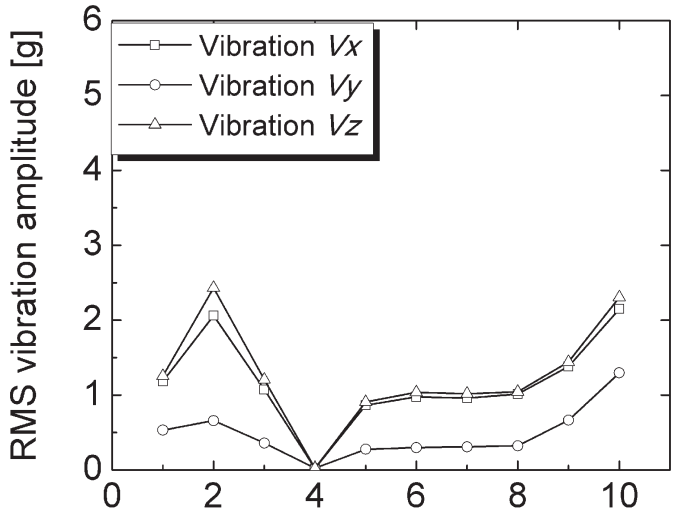

c)

\section{Cutting time [s]}

Fig. 8. The vibration amplitude vs. the cutting time at the cutting speed of $225 \mathrm{~m} / \mathrm{min}$ at the feed rate of a) $0.01 \mathrm{~mm} / \mathrm{rev}$, b) 0.04 $\mathrm{mm} / \mathrm{rev}$, and c) $0.10 \mathrm{~mm} / \mathrm{rev}$; tool inserts \#4 to \#6 were employed 
amplitude. Figs. 7 and 8 show, respectively, the effect of dynamic tool-edge wear on the cutting vibrations under varying cutting speed $[125,225$, and $275 \mathrm{~m} /$ $\mathrm{min}]$ and varying feed rate [0.01, 0.04, and $0.1 \mathrm{~mm} /$ rev] conditions. Except for Fig. 8b, two vibration components $\left[V_{x}\right.$ in the cutting speed direction and $V_{z}$ in the depth of cut direction] exhibit higher values and have values very close to each other. The observation on all the six sub-figures in these two figures leads to a same conclusion: There is no obvious varying trend for the $R M S$ vibration amplitude as tool-edge wear dynamically develops. The "ups and downs" of the vibration amplitude are found all over the map in the six sub-figures. In contrast, the cutting forces vary in a certain pattern as shown in previous Figs. 5 and 6 .

Based on the results shown in Figs. 5 to 8, two important conclusions are drawn. 1) Compared to the cutting forces, the cutting vibrations are more sensitive to dynamic tool-edge wear. Because tool-edge wear is complex, the vibration signals are also complex. 2) The traditional time domain analysis based on the $R M S$ vibration amplitude is not helpful in explaining and showing the dynamic development of tool-edge wear. No distinct features from the time domain vibration signals can be extracted to effectively corelate the cutting vibrations with dynamic tool-edge wear. Wavelet packet transform (WPT), a modern advanced signal-processing technique, was thus employed and is described as follows.

\section{TIME-FREQUENCY ANALYSIS VIA WAVELET PACKET TRANSFORM}

Compared to other signal processing techniques (such as fast Fourier transform, FFT) that relate tool wear (primarily crater and flank wear) and the cutting vibrations [20] to [23], wavelet packet transform not only helps in identifying the changes in the vibration signals in different frequency bands that are associated with dynamic tool-edge wear, but also helps in identifying the most important features of vibration signals that are most sensitive to dynamic tool-edge wear. A brief introduction to wavelet packet transform is first provided to better understand the wavelet packet algorithm employed in the present study.

\subsection{Wavelet Packet Transform}

Wavelet transform (WT) is a mathematical function that multiplies the signal during all its length, with elongated and compressed versions of a mother wavelet. A signal is decomposed into a low frequency component (called approximation) and a high-frequency component (called detail). The approximation in turn is then decomposed into a second level of approximation and detail and this process is repeated. WT can extract signal information in the time domain at different frequency bands and provides flexible time-frequency resolution properties [14]. However, WT has one drawback that the frequency resolution is rather poor in the high-frequency region. Thus, it faces difficulties in discriminating between signals having close highfrequency components [15].

To overcome the drawback of wavelet transform, wavelet packet transform is used as one of the most generalized signal decomposition methods. Wavelet packets are alternative wavelet bases formed by taking linear combination of the usual wavelet functions. These bases inherit properties, e.g., orthonormality and time-frequency localization, from their wavelet functions [24]. In wavelet packet transform, both the approximation and detail parts are decomposed. A wavelet packet function is a function with three indices $(i, j, k)$ satisfying:

$$
W_{j, k}^{n}(t)=2^{j / 2} W^{n}\left(2^{j} t-k\right)
$$

where $j$ and $k$ are index of scale and translation operations, respectively; the index $n$ is called the modulation parameter or the oscillation parameter and $n=0,1,2, \ldots, 2^{j-1}$.

Wavelet packet functions are defined by:

$$
\begin{gathered}
W_{2 n}(x)=\sqrt{2} \sum_{k} h(k) W_{n}(2 x-k), \\
W_{2 n+1}(x)=\sqrt{2} \Sigma_{k} g(k) W_{n}(2 x-k),
\end{gathered}
$$

where $h(k)$ and $g(k)$ are the low-pass and high-pass filters; $W_{0}(x)=\phi(x)$ is the scaling function; and $W_{1}(x)=\psi(x)$ is the wavelet function.

The discrete filters $h(k)$ and $g(k)$ are quadrature mirror filters associated with scaling function and wavelet function [25]. To measure specific timefrequency information in a signal, the inner product of the signal and a particular basis function is taken. The wavelet packet coefficients of a function $f(x)$ is computed as:

$$
W_{j, n, k}=<f, W_{j, k}^{n}>=\int f(x) W_{j, k}^{n}(x) \mathrm{d} x .
$$

The whole set of the orthonormal bases is called a wavelet packet library. The discrete wavelet packet transform is then expressed as:

$$
W_{j+1,2 n}=\boldsymbol{H} W_{j, n},
$$


where $\boldsymbol{H}=\left\{h_{1}\right\}_{1 \in Z}$ and $\boldsymbol{G}=\left\{g_{1}\right\}_{1 \in Z}$ are the lowpass and high-pass filter matrices; $W_{0,0}$ represents the measured signal; $W_{j, n}$ is the wavelet packet where $j$ and $n$ indicate the level of the decomposition and the position at that level, respectively.

Finally, the reconstruction of the wavelet packets can be represented as:

$$
W_{j, n}=\boldsymbol{H}^{*} W_{j+1,2 n}+\boldsymbol{G}^{*} W_{j+1,2 n+1},
$$

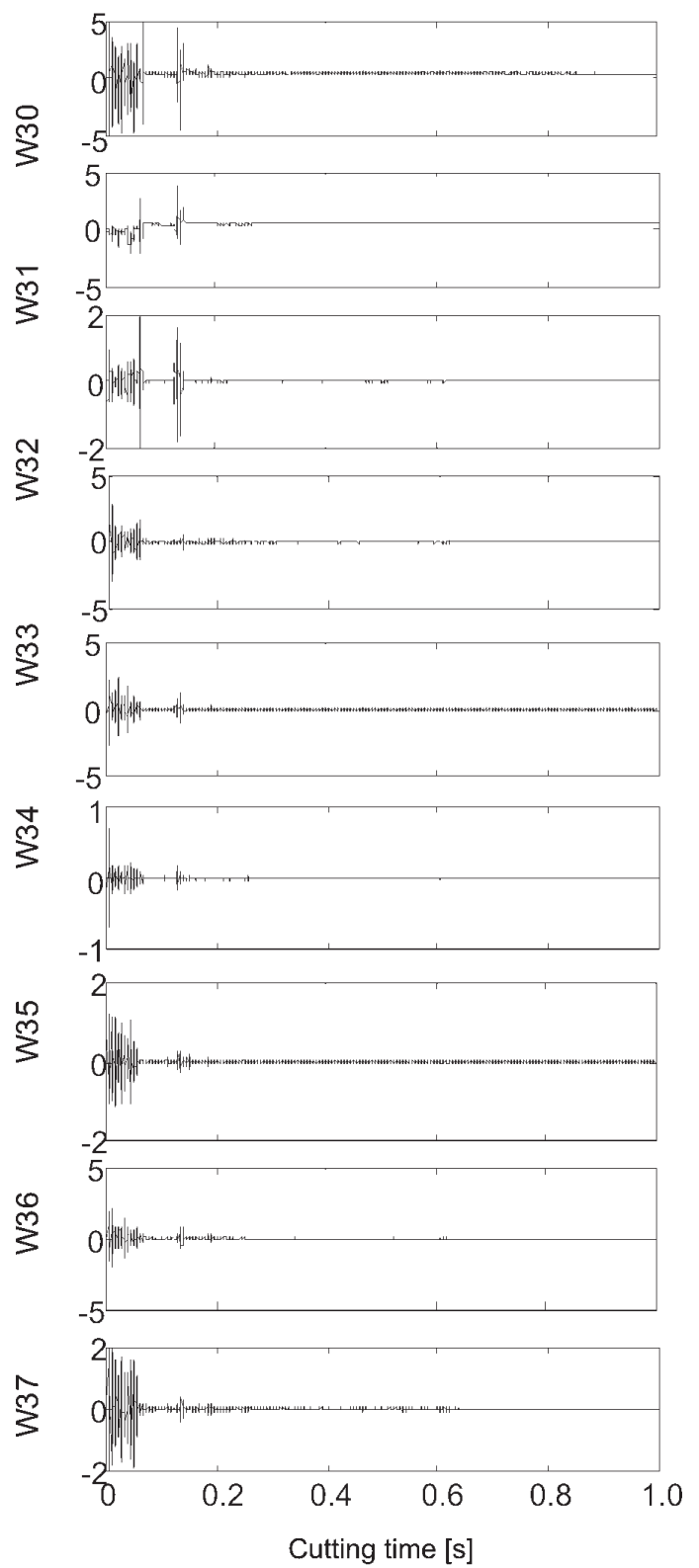

Fig. 9. Representative examples of the third-level wavelet packet decomposition of vibration signals during the cutting time of 1 to 2 seconds where $\boldsymbol{H}^{*}$ and $\boldsymbol{G}^{*}$ represent the conjugate matrix of $\boldsymbol{H}$ and $\boldsymbol{G}$, respectively [14].

\subsection{Results and Analysis via Wavelet Packet Transform}

Figs. 9 and 10 provide two representative examples of the third-level wavelet packet decomposition of vibration signals acquired at a sampling frequency of $10 \mathrm{KHz}$ using Daubechies 8 wavelet function. The
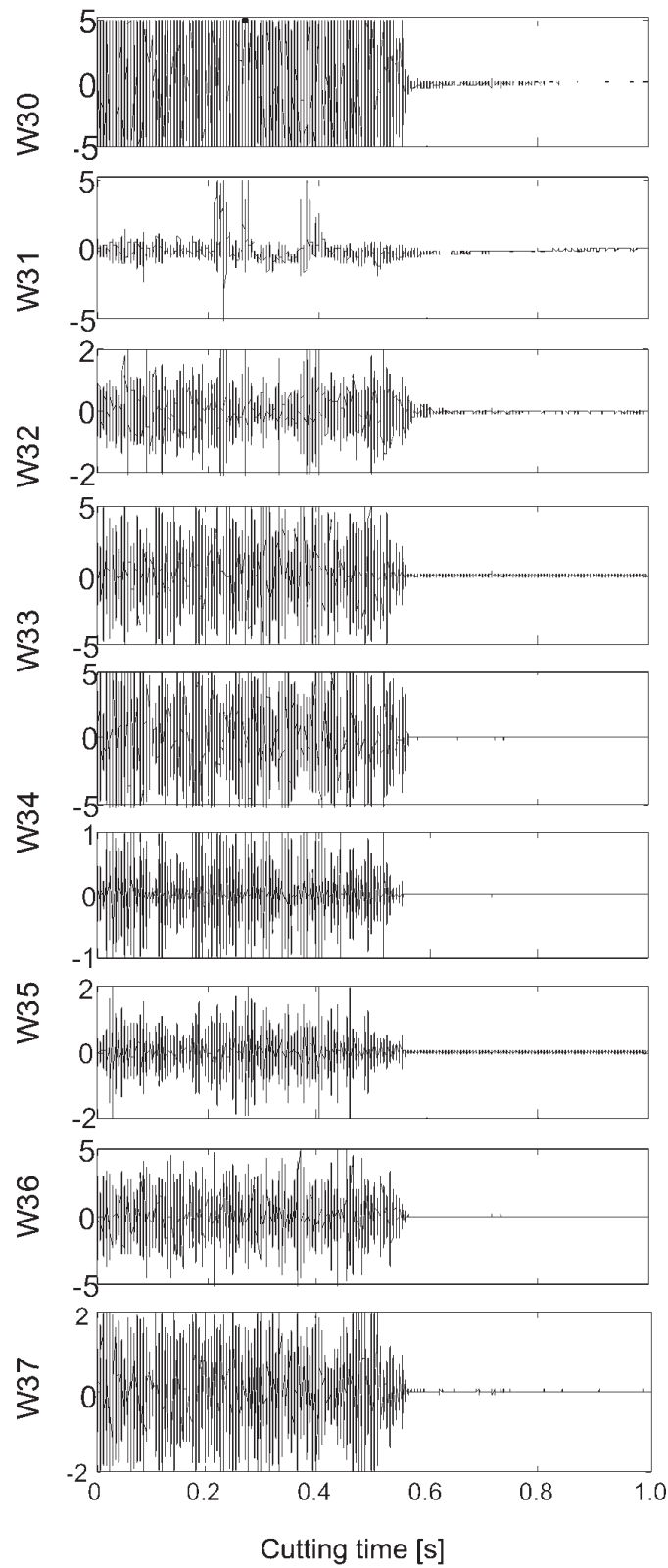

Fig. 10. Representative examples of the third-level wavelet packet decomposition of vibration signals during the cutting time of 8 to 9 seconds 
figures contain 8 frequency bands ( 8 wavelet packets W30 through W37) generated at the cutting time of 2 seconds and 9 seconds. The tool insert \#3 was employed at the cutting speed of $275 \mathrm{~m} / \mathrm{min}$, the feed rate of $0.10 \mathrm{~mm} / \mathrm{rev}$, and the depth of cut of $0.80 \mathrm{~mm}$.

A comparison between Figs. 9 and 10 shows that the energy in different frequency bands during the cutting time of 1 to 2 seconds is less than that during the cutting time of 8 to 9 seconds. This means that the energy in different frequency bands increases as tool-edge wear increases. As shown in the tool-edge wear profile in Fig. 3, tool-edge wear is less during 1 to 2 seconds (the tool edge is relatively fresh) and becomes severer during 8 to 9 seconds (the initiallyround tool edge becomes "flat" at the center and outer measurement points). In addition, when the tool is sharp (fresh), lower frequency vibration is mainly excited. As tool-edge wear progresses, it excites different frequencies of vibrations of the cutting tool, tool holder, and machine structure, resulting in the higher frequency components becoming dominant in the signal.

To further extract from wavelet packets for different tool-edge wear conditions, the $R M S$ value of wavelet coefficients in each frequency band was calculated using :

$$
\operatorname{RMSW}_{(3, p)}=\sqrt{\sum_{k=1}^{m} \frac{\left(W_{(3, p)}(k)-\bar{W}_{(3, p)}\right)^{2}}{m}},
$$

where 3 stands for the third-level decomposition; $\mathrm{p}$ is the number of wavelet packets ( 8 in this case); $W_{(3, p)}(k)$ is the values of the individual wavelet packet coefficients; $\bar{W}_{(3, p)}$ is the mean value of the wavelet packet coefficient; and $\mathrm{m}$ is the number of coefficients in each wavelet packet.

The RMS of wavelet packet coefficients was calculated for different cutting conditions for each experiment. It has been found that compared to other wavelet packet coefficients, coefficients $W_{(3,2)}$ and $W_{(3,3)}$ [simply written as $W 32$ and $W 33$ ] are more sensitive to dynamic tool-edge wear. As an example, Figs. 11 and 12 show the RMS W33 wavelet coefficient [corresponding to a frequency band of 1,875 to 2,500 $\mathrm{Hz}]$ and the corresponding $R M S$ vibration amplitude [in the cutting speed, $x$-direction] under varying cutting speed and feed rate conditions. The W33 wavelet packet coefficient (in the time-frequency domain) shows an exact replication of the trend of the variation of $R M S$ values of cutting vibrations (in the time domain) with time under various cutting conditions in both Figs. 11 and 12.

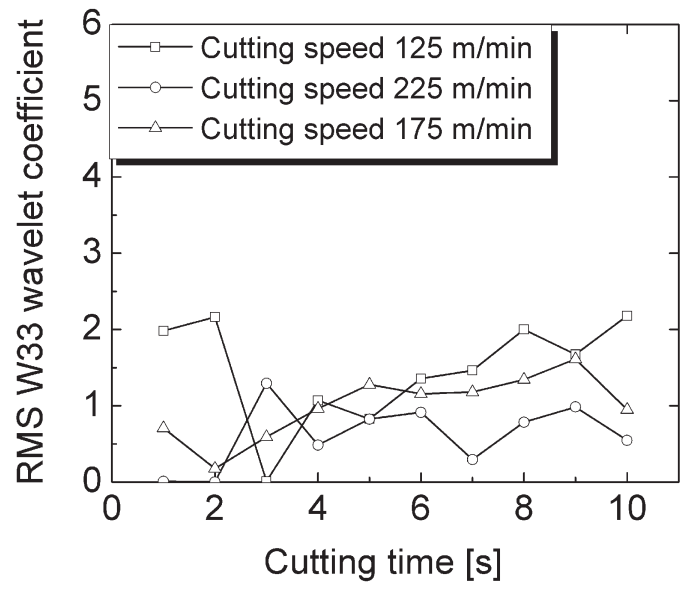

a)

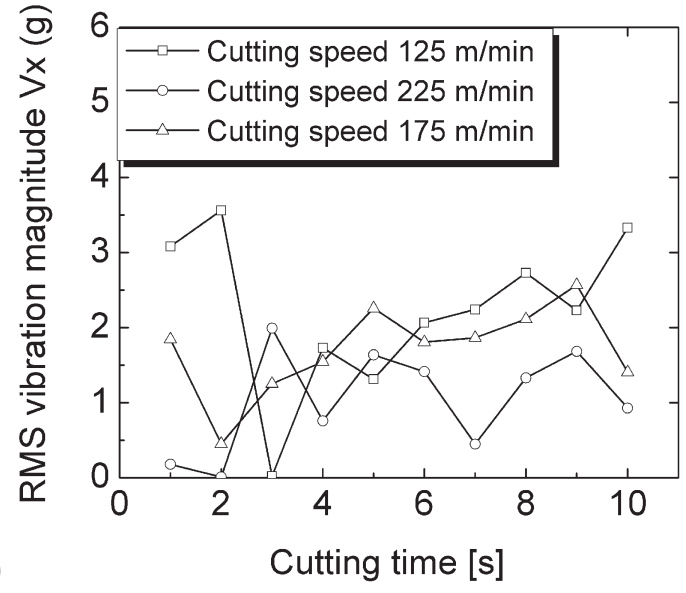

Fig. 11. a) RMS W33 coefficient and b) the RMS vibration amplitude at varying cutting speeds

The W33 wavelet packet coefficient is the most sensitive coefficient that can be employed as an important input for pattern recognition techniques, e.g., artificial neural networks, in a future tool-edge wear monitoring system. A detailed discussion on how to incorporate the W33 coefficient into a tool wear monitoring system [26] and [27] that includes tool-edge wear monitoring is beyond the scope of this paper.

Finally, to demonstrate the advantage of wavelet packet transform over the conventional FFT analysis, Fig. 13 shows two FFT frequency spectra of vibration signals during the cutting time of 8 to 9 seconds and 1 to 2 seconds. Although FFT analysis can identify the variation of vibration amplitude at different frequencies in light and severe tool-edge wear, FFT analysis fails to reveal which particular frequency band (over a wide range of frequencies) directly corresponds to tool-edge wear. In other words, FFT analysis fails to identify the particular frequency band 
that can be employed to monitor and detect tool-edge wear.

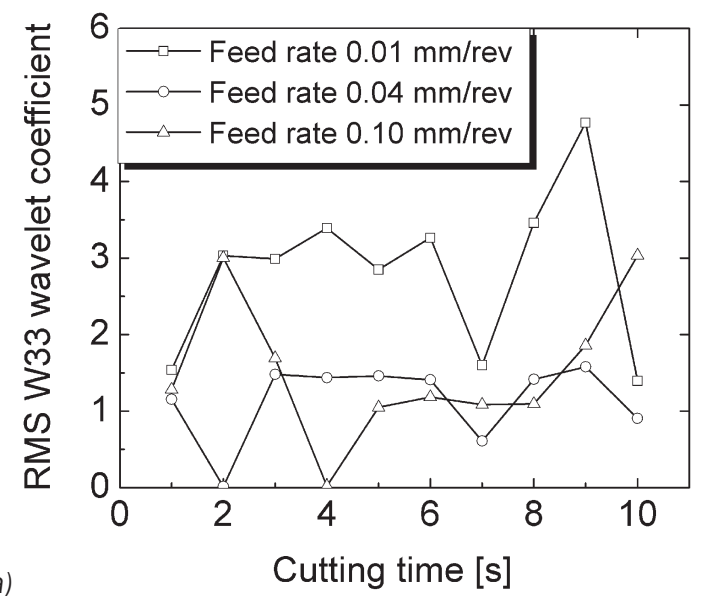

a)

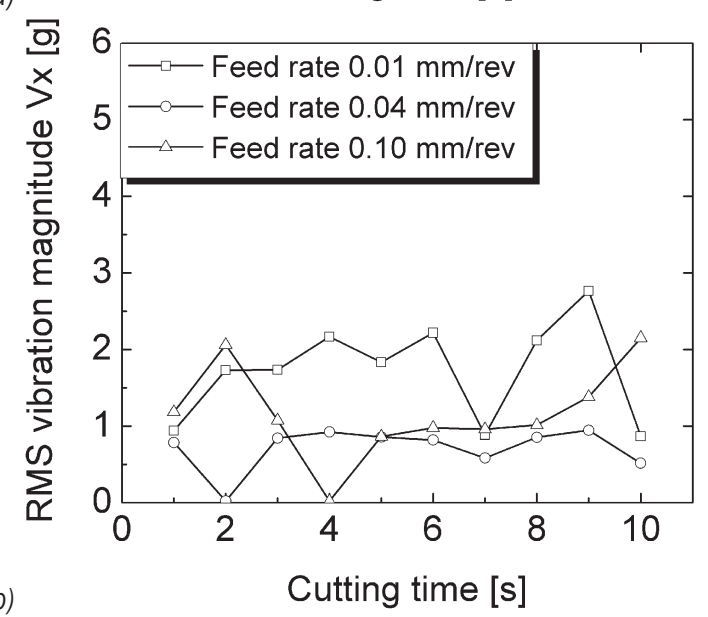

Fig. 12. a) RMS W33 coefficient and b) the RMS vibration amplitude at varying feed rates

\section{CONCLUSIONS}

As tool-edge geometry plays a significant role in machining at small feed rates [28] and [29], tool-edge wear significantly contributes to early tool failure and deteriorated quality of machined components and parts. Compared to tool crater wear and flank wear that have been well studied for decades, there has been little study on tool-edge wear. This paper has performed a fundamental study of tool-edge wear in high-speed finish machining of nickel-based superalloy Inconel 718. The emphasis of the present study is on the correlation among tool-edge wear, the cutting forces and vibrations. The major research findings are summarized in the following paragraphs.

1) As the cutting continues, tool-edge wear develops either rapidly or slowly, depending on the initial tool-edge geometry and the cutting conditions employed.

2) The amount of tool-edge wear varies at different measurement points that correspond to different undeformed chip thicknesses and tool-chip friction conditions at particular measurement points. In general, tool-edge wear increases from the outer point, through the center point, to the inner point. Tool-edge wear also increases as the feed rate increases.

3) The tool-edge wear profile dynamically varies and is often in irregular shape, adding to the complexity of dynamic tool-edge wear.

4) The effect of dynamic tool-edge wear on the cutting forces highly depends on particular cutting conditions employed as well as the initial tool-edge geometry. All three components of the cutting forces increase with increasing tool-edge wear at the feed rates of 0.01 and $0.10 \mathrm{~mm} / \mathrm{rev}$. The increasing trend of the cutting forces is not significant at the feed rate of $0.04 \mathrm{~mm} / \mathrm{rev}$.

5) No obvious varying trend was observed for the $R M S$ vibration amplitude as tool-edge wear develops. The traditional time domain analysis based on the RMS vibration amplitude is not helpful in explaining and showing the dynamic development of tool-edge wear.
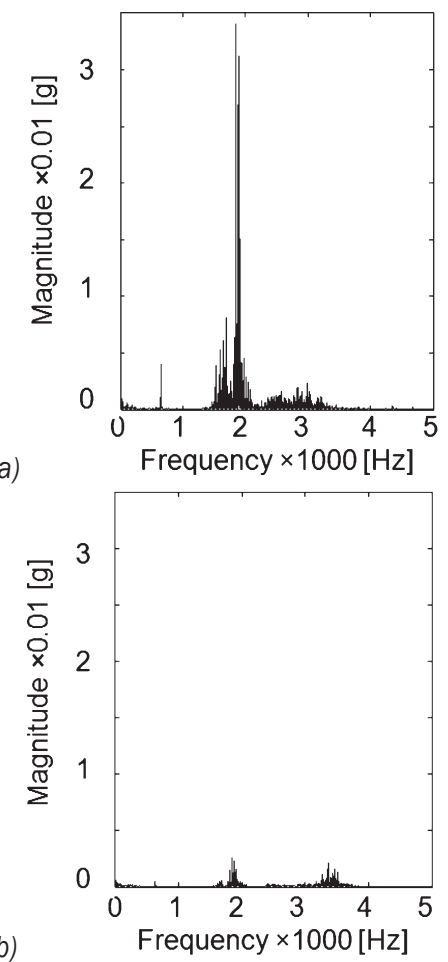

Fig. 13. FFT frequency spectrum of the vibration signals during the cutting time of a) 8 to 9 seconds and b) 1 to 2 seconds 
6) As one of the most generalized signal decomposition methods used in the timefrequency domain analysis, the wavelet packet transform helps in identifying the changes in the vibration signals in different frequency bands. Under the initial tool geometry and cutting conditions employed in the present study, the W33 wavelet packet coefficient is identified as the most sensitive to dynamic tool-edge wear, and it can be employed as an important input for pattern recognition techniques in a future tooledge wear monitoring system.

\section{REFERENCES}

[1] Liu, K., Li, X.P., Rahman, M., Liu, X.D. (2003). CBN tool wear in ductile cutting of tungsten carbide. Wear, vol. 255 , no. 2 , p. 1344-1351, DOI:10.1016/S00431648(03)00061-9.

[2] Kopac, J. (2004). Cutting-tool wear during high-speed cutting. Strojniški vestnik - Journal of Mechanical Engineering, vol. 50, no. 4, p. 195-205.

[3] Antic, A., Hodolic, J., Sokovic, M. (2006). Development of a neural-networks tool-wear monitoring system for a turning process. Strojniški Vestnik - Journal of Mechanical Engineering, vol. 52, no. 11, p. 763-776.

[4] Shaw, M.C. (2005). Metal cutting principles, $2^{\text {nd }}$ ed. Oxford University Press, New York.

[5] Trent, W.M., Wright, P.K. (2000). Metal cutting, 4th ed., Butterworth-Heinemann, Woburn

[6] Kumar, B.V.M., Kumar, J.R., Basu, B. (2007). Crater wear mechanisms of TiCN-Ni-WC cermets during dry machining. International Journal of Refractory Metals and Hard Materials, vol. 25, no. 5-6, p. 392-399, DOI:10.1016/j.ijrmhm.2006.12.001.

[7] Subramanian, S.V., Ingel, S.S., Kay, D.A.R. (1993). Design of coatings to minimize tool crater wear. Surface Coating Technology, vol. 61, no. 1-3, p. $293-$ 299, DOI:10.1016/0257-8972(93)90241-F.

[8] Dutta, A.K., Chattopadhyaya, A.B., Ray, K.K. (2006). Progressive flank wear and machining performance of silver toughened alumina cutting tool inserts. Wear, vol. 261, no. 7-8, p. 885-895, DOI:10.1016/j. wear.2006.01.038.

[9] Lim, S.C., Lim, C.Y.H., Lee, K.S. (1995). The effects of machining conditions on the flank wear of TiNcoated high-speed steel tool inserts. Wear, vol. 181, no. 1-2, p. 901-912, DOI:10.1016/0043-1648(95)80019-0.

[10] Sarwar, M., Persson, M., Hellbergh, H. (2009). Wear of the cutting edge in the bandsawing operation when cutting austenitic 17-7 stainless steel. Wear, vol. 263, no. 7, p. 1438-1441, DOI:10.1016/j.wear.2006.12.066.

[11] Wu, Q., Fang, N. (2006). Effect of tool-edge wear in high-speed machining of superalloy Inconel 718. Transactions of North America Manufacturing Research Institution, vol. 34, p. 397-402.
[12] Li, X., Wu, J. (2000). Wavelet analysis of acoustic emission signals in boring. Journal of Engineering Manufacture, vol. 214, no. 5, p. 421-424, DOI: $10.1243 / 0954405001518206$.

[13] Xu, C.W., Chen, H.L., Liu, Z., Cheng, Z.W. (2009). Condition monitoring of milling tool wear based on facture dimension of vibration signals. Strojniški Vestnik - Journal of Mechanical Engineering, vol. 55, no. 1, p. 15-25.

[14] Patra, K., Pal, S.K., Bhattacharyya, K. (2007). Application of wavelet packet analysis in drill wear monitoring. Machining Science and Technology, vol. 11, no. 3, p. 413-432.

[15] Yen, G.G., Lin, K.C. (2000). Wavelet packet feature extraction for vibration monitoring. IEEE Transactions on Industrial Electronics, vol. 47, no. 3, p. 650-667, DOI:10.1109/41.847906.

[16] Choudhury I.A., El-Baradie, M.A. (1998). Machining nickel base superalloys: Inconel 718. Journal of Engineering Manufacture, vol. 212, no. B3, p. 195-206, DOI:10.1243/0954405981515617.

[17] Fang, N., Wu, Q. (2009). A comparative study of the cutting forces in high speed machining of Ti-6AL-4V and Inconel 718 with a round edge tool. Journal of Materials Processing Technology, vol. 209, no. 9, p. 4385-438, DOI:10.1016/j.jmatprotec.2008.10.013.

[18] Ezugwu, E.O., Fadare, D.A., Bonney, J., Da Silva, R.B., Sales, W.F. (2005). Modelling the correlation between cutting and process parameters in high-speed machining of Inconel 718 alloy using an artificial neural network. International Journal of Machine Tools and Manufacture, vol. 45, no. 12-13, p. 1375-1385, DOI:10.1016/j.ijmachtools.2005.02.004.

[19] Fang, N. (2003). Slip-line modeling of machining with a rounded-edge tool, part I: new model and theory. Journal of the Mechanics and Physics of Solids, vol. 51, no. 4, p. 715-742, DOI:10.1016/S00225096(02)00060-1.

[20] Xue, C.W., Chen, H.L.A. (2007). A research of tool wear recognizing based on wavelet packet pretreated and neural network. Journal of System Design and Dynamics, vol. 1, no. 4, p. 760-770, DOI:10.1299/ jsdd.1.760.

[21] Alonso, F.J., Salgado, D.R. (2008). Analysis of the structure of vibration signals for tool wear detection. Mechanical Systems and Signal Processing, vol. 22, no. 3, p. 735-748, DOI:10.1016/j.ymssp.2007.09.012.

[22] Orhan, S., Er, A.O., Camuscu, N., Aslan, E. (2007). Tool wear evaluation by vibration analysis during end milling of AISI D3 cold work tool steel with 35 HRC hardness. NDT \& E International, vol. 40, no. 2, p. 121 126, DOI:10.1016/j.ndteint.2006.09.006.

[23] Schmitz, T., Davies, M., Medicus, K., Snyder, J. (2001). Improving high-speed machining material removal rates by rapid dynamic analysis. CIRP Annals, vol. 50, no. 1 , p. 263-268, DOI:10.1016/S0007-8506(07)621192. 
[24] Coifman, R.R., Wickerhauser, M.V. (1992). Entropybased algorithms for best basis selection. IEEE Transactions Information Theory, vol. 38, p. 713-718, DOI:10.1109/18.119732.

[25] Mallat, S. (1989). A theory of multiresolution signal decomposition: the wavelet representation. IEEE Transactions on Pattern Analysis and Machine Intelligence, vol. 11, no. 7, p. 674-693, DOI:10.1109/34.192463.

[26] Rehorn, A.G., Jiang, J., Orban, P.E. (2005). Stateof-the-art methods and results in tool condition monitoring: a review. International Journal of Advanced Manufacturing Technology, vol. 26, no. 7-8, p. 693-710, DOI:10.1007/s00170-004-2443-6.
[27] Sick, B. (2002). On-line and indirect tool wear monitoring in turning with artificial neural networks: A review of more than a decade of research. Mechanical Systems and Signal Processing, vol. 16, no. 4, p. 487546, DOI:10.1006/mssp.2001.1460.

[28] Liu, K., Li, X.P., Rahman, M., Neo, K.S., Liu, X.D. (2007). A study of the effect of tool cutting edge radius on ductile cutting of silicon wafers. International Journal of Advanced Manufacturing Technology, vol. 32, no. 7-8, p. 631-637, DOI:10.1007/s00170-0050364-7.

[29] Pušavec, F., Govekar, E., Kopač, J., Jawahir, I.S. (2011). The influence of cryogenic cooling on process stability in turning operations. CIRP Annals Manufacturing Technology, vol. 60, p. 101-104. 